\title{
Prediction of the peak velocity of blasting vibration based on various models at Ninh Dan quarry, Thanh Ba district, Phu Tho province
}

\section{An Dinh Nguyen 1,*, Hieu Quang Tran 1, Bao Dinh Tran 1, Phonepaserth Soukhanouvong ${ }^{2}$}

${ }^{1}$ Faculty of Mining, Hanoi University of Mining and Geology, Vietnam

${ }^{2}$ PhD Candidate Surface Mining Department, Hanoi University of Mining and Geology, Vietnam

\begin{abstract}
ARTICLE INFO
ABSTRACT

Article history:

Received 05th Apr. 2020

Revised $13^{\text {rd }}$ July 2020

Accepted 31 st Aug. 2020

Keywords:

Blasting,

Ground vibration,

Ninh Dan quarry

Peak particle velocity.

In mining industry, blasting operation is effective method to fragment rocks, supporting for the next operations in surface mines such as loading, and hauling works. However, blasting operation also impacts adversely on buildings and the surrounding environment, in which the vibration wave is one of the most severe impacts. Therefore, the implementation of the forecasting models of vibration speed contributes significantly to guarantee the safety of buildings located within the impact areas of the vibration wave. This paper employs the monitoring results of blasting activity at the Ninh Dan limestone quarry situated in Thanh Ba district, Phu Tho province, to develop different forecasting models that determine the effects of the ground vibration speed in the surrounding buildings. The results show that the models USBM and Ambraseys Hendron having more accuvate prediction than other models.
\end{abstract}

Copyright (C) 2020 Hanoi University of Mining and Geology. All rights reserved.

${ }^{*}$ Corresponding author

E - mail: nguyendinhan@humg.edu.vn

DOI: 10.46326/JMES.2020.61(4).11 


\title{
Tạp chí Khoa học Kỹ thuật Mỏ - Địa chất
}

\section{Đánh giá một số mô hình dự báo chấn động khi nổ mìn tại mỏ đá vôi Ninh Dân, huyện Thanh Ba, tỉnh Phú Thọ}

\author{
Nguyễn Đình An 1,*, Trần Quang Hiếu 1, Trần Đình Bão 1, Phonepaserth \\ Soukhanouvong ${ }^{2}$ \\ ${ }^{1}$ Khoa Mỏ, Trường Đại học Mỏ - Địa chất, Việt Nam \\ ${ }^{2}$ Nghiên cứu sinh Bộ môn Khai thác lộ thiên, Trường Đại học Mỏ - Địa chất, Việt Nam
}

\begin{abstract}
THÔNG TIN BÀI BÁO TÓM TẮT
Quá trình:

Nhận bài $05 / 4 / 2020$

Sưa xong 13/7/2020

Chấp nhận đăng 31/8/2020

Tù̀ khóa:

Mỏ Ninh Dân

Nổ mìn,

Sóng chấn động,

Tốc độ dao động.

Trong khai thác mỏ, nổ mìn là phương pháp phá vỡ đất đá hiệu quả phục vụ cho các khâu tiếp theo là xúc bốc, vận tải,... Tuy nhiên, nổ mìn cũng gây nhiều tác động có hại đến các công trình bảo vệ và môi trường xung quanh, trong đó đáng kể nhất là tác dụng của sóng chấn động nổ mìn. Do vậy, việc sử dụng các mồ hình dự báo tốc độ dao động nền đất do nổ mìn sinh ra đóng một vai trò rất quan trọng nhằm đảm bảo an toàn đối với các công trình cẩn bảo vệ nằm trong vùng ảnh hưởng của sóng chấn động nổ mìn. Bài báo đã sử dụng các kết quả đo giám sát nố mìn tai mỏ đá vôi Ninh Dân, huyện Thanh Ba, tỉnh Phú Thọ và sư dung các mô hình khác nhau để dư báo tốc độ dao động của nền công trình ảnh hưởng đến các công trình bảo vệ xung quanh. Kết quả cho thấy: mô hình USBM và Ambraseys Hendron có độ chính xác cao hơn các mô hình khác.
\end{abstract}

C 2020 Trường Đại học Mỏ - Địa chất. Tất cả các quyền được bảo đảm.

\section{Mở đầu}

Trong khai thác mỏ, nổ mìn là một trong những phương pháp phá vỡ đất đá hiệu quả và được sử dụng khá phổ biến hiện nay trên các mỏ khai thác đá vôi ở Việt Nam. Tuy nhiên, trong quá trình nổ mìn, không phải toàn bộ năng lượng sinh ra của chất nổ được sử dụng để phá vỡ đất đá mà thực tế chỉ có một phần rất nhỏ năng lượng trên có tác dụng đập vỡ đất đá, còn lại phần lớn năng lượng

*Tác giả liên hệ

E - mail: nguyendinhan@humg.edu.vn DOI: 10.46326/JMES.2020.61(4).11 sinh ra những công vô ích như sóng chấn động lan truyền trong môi trường đất đá, sóng va đập lan truyền trong không khí, đá bay và sinh ra nhiều bụi, tiếng ồn,... Những tác hại trên luôn tồn tại trong các vụ nổ mìn, gây ảnh hưởng không nhỏ tới sự an toàn của các công trình bảo vệ xung quanh, môi trường sinh thái, an toàn lao động, đời sống dân sinh (Hình 1). Mức độ ảnh hưởng của những tác động có hại này phụ thuộc vào nhiều yếu tố tự nhiên - kỹ thuật khác nhau trong công tác nổ mìn (Nhữ Văn Bách, 2015).

Tiêu chuẩn tổng quát nhất đánh giá tác dụng chấn động khi nổ mìn là tốc độ dao động riêng của các toà nhà, các công trình dân dụng và công nghiệp, đây là thông số chủ yếu để quyết định tác 


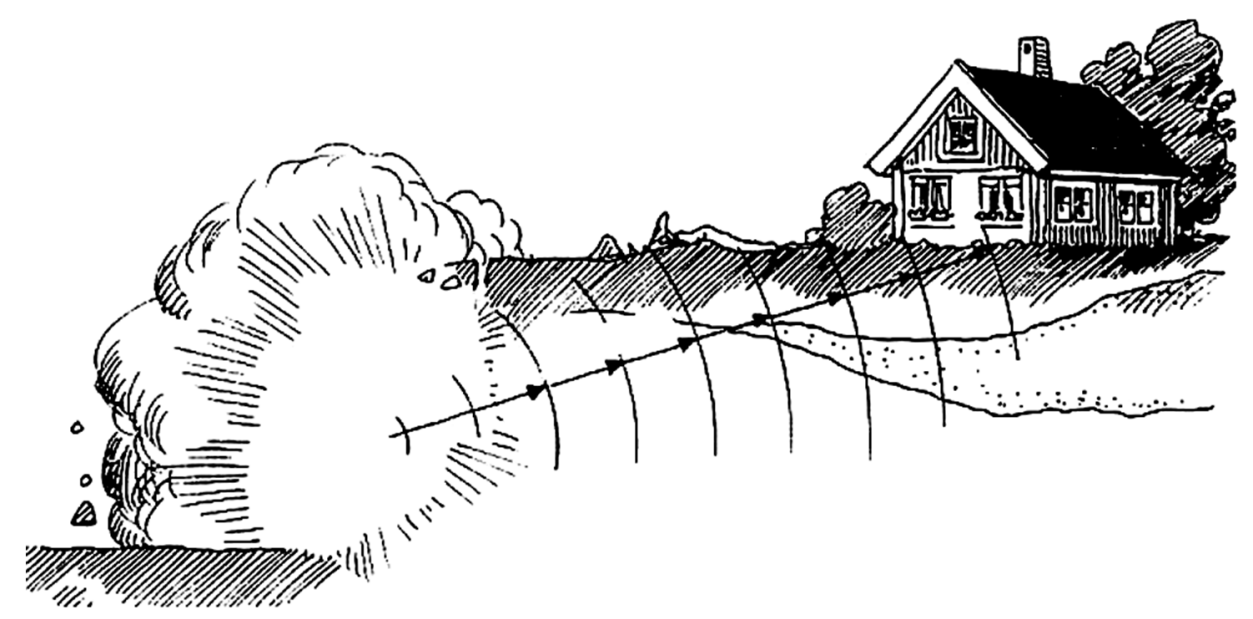

Hình 1. Minh họa ảnh hưởng của chấn động do nổ mìn.

dụng chấn động của các loại sóng khác nhau đối với công trình (Kutuzov, 1992; Xadopski, 2004; Ganaponxki và nnk., 2007).

Để dự đoán tốc độ dao động nền đất có thể sử dụng nhiều mô hình dự báo khác nhau dựa trên kết quả đo tốc độ dao động lớn nhất (PPV, mm/s). Nhìn chung, các mô hình dự báo đưa ra có dạng thống nhất, trong đó có chứa hai thông số quan trọng là khối lượng thuốc nổ sử dụng lớn nhất cho mỗi cấp vi sai $(Q)$ và khoảng cách tính từ vị trí nổ mìn đến điểm đặt máy đo cần giám sát chấn động $(R)$, chỉ có các chỉ số mũ và các hệ số chấn động $(\mathrm{K})$ là khác nhau tuỳ thuộc vào điều kiện cụ thể của bãi nổ (xác định bằng thực nghiệm) (Nhữ Văn Bách và nnk., 2013; Nguyễn Đinh An và nnk., 2011; Drukovanui, 1973).

Trong nghiên cứu này, nhóm tác giả đã thực hiện giám sát chấn động nổ mìn tại mỏ đá vôi Ninh Dân huyện Thanh Ba, tỉnh Phú Thọ. Trên cơ sở các kết quả đo giám sát, nhóm tác giả đã sử dụng các mô hình khác nhau để dự báo tốc độ dao động lớn nhất của nền công trình (PPV, $\mathrm{mm} / \mathrm{s})$ do ảnh hưởng của nổ mìn, để từ đó có thể điều chỉnh lại các thông số của vụ nổ trong hộ chiếu nổ mìn nhằm đảm bảo an toàn và nâng cao chất lượng đập vỡ đất đá cho mỏ đá vôi Ninh Dân.

\section{Các mô hình dự báo chấn động khi nổ mìn}

Các nhà khoa học đều cho rằng khó có thể xác định được tốc độ dao động của nền công trình khi nổ mìn bằng cách sử dụng phương trình động lực học vì sự thay đổi quy mô của một đợt nổ, sơ đồ nổ, điều kiện địa chất, (Xadopski, M. A., 2004), (Nhữ Văn Bách, 2015). Chính vì vậy để dự đoán được tốc độ dao động lớn nhất của nền đất bằng cách sử dụng các công thức thực nghiệm trên cơ sở các kết quả giám sát được của vụ nổ được thể hiện trong Bảng 1.

Bảng 1. Các mô hình dự báo tốc độ dao động nền đất dựa trên hệ số tỉ lệ khoảng cách.

\begin{tabular}{|c|c|c|}
\hline TT & $\begin{array}{l}\text { Phưong pháp tiếp cận: Hệ số tỉ lệ khoảng cách } \\
\text { lũy tiến giảm dần }(R / Q), D s\end{array}$ \\
\hline 1 & USBM (1959) & $P P V=K\left[\frac{R}{\sqrt{Q}}\right]^{-b}$ \\
\hline 2 & $\begin{array}{c}\text { Ambraseys } \\
\text { Hendron (1968) }\end{array}$ & $P P V=K\left[\frac{R}{\sqrt[3]{Q}}\right]^{-b}$ \\
\hline & $\begin{array}{c}\text { Phưong pháp tiếp cận : Hệ số tỉ lệ khoảng cách } \\
\text { tăng lũy tiến (Q/R), Ds }\end{array}$ \\
\hline 1 & $\begin{array}{c}\text { Indian Strandard } \\
\text { (1973) }\end{array}$ \\
\hline 2 & $\begin{array}{c}\text { Langefors- } \\
\text { Kihlstrom (1963) }\end{array}$ & $P P V=K\left[\frac{Q_{\max }}{R^{2 / 3}}\right]^{b}$ \\
\hline
\end{tabular}

Trong đó: $P P V$ - tốc độ dao động của nền đất, $\mathrm{mm} / \mathrm{s}$; $Q$ - khối lượng thuốc nổ sử dụng lớn nhất cho mỗi cấp vi sai, $\mathrm{kg}$; $R$ - Khoảng cách từ bãi nổ đến điểm đo, $\mathrm{m} ; K, b, n, \alpha$ là các hệ số xác định bằng thực nghiệm.

Bảng 1 giới thiệu các mô hình dự báo khác nhau để xác định tốc độ dao động gây ra bởi vụ nổ dựa trên hai khái niệm tỉ lệ khoảng cách khác nhau. Nhóm mô hình dự báo của USBM (1959) và Ambraseys Hendron (1968) dựa trên hệ số tỉ lệ khoảng cách lũy tiến giảm dần là tỉ số giữa khoảng cách và khối lượng thuốc nổ cho một đợt nổ vi sai $(R / Q)$, nghĩa là khoảng cách tăng thì tốc độ dao động giảm (Dehghani, 2011), (Stig O Olofsson, 
1997). Các mô hình dự báo này được nhiều tác giả sử dụng phổ biến hiện nay. Nhóm mô hình dự báo của Indian Strandard (1973) và LangeforsKihlstrom (1963) dựa trên hệ số khoảng cách tăng lũy tiến là tỉ số giữa khối lượng thuốc nổ và khoảng cách $(Q / R)$ nghĩa là hệ số khoảng cách này sẽ tỉ lệ thuận với tốc độ dao động (Khandelwal và Singh, 2009,2007). Nói chung các mô hình dự báo này đều chính xác chỉ có cách tiếp cận về mặt toán học là khác nhau.

\section{3. Đánh giá tốc độ dao động nền đất do nổ mìn khi sử dụng các mô hình dự báo khác nhau}

Để dự báo tốc độ dao động lớn nhất của nền đất theo các mô hình khác nhau, nhóm nghiên cứu đã sử dụng thiết bị Blastmate III và Micromate để tiến hành đo giám sát các vụ nổ tại mỏ đá vôi Ninh Dân. Hiện tại mỏ đá vôi Ninh Dân đang nổ mìn vi sai phi điện là nổ mìn vi sai theo sơ đồ qua từng lỗ (thể hiện chế độ đặt tải tối đa). Các thông số nổ mìn của các vụ nổ được thể hiện ở Bảng 2; sơ đồ đấu ghép mạng nổ giới thiệu ở Hình 2; vị trí giám sát nổ mìn và kết quả giám sát nổ mìn được trình bày ở Hình 3 và Hình 4 . Trong Bảng 3 tổng hợp các các kết quả giám sát, khoảng cách đo và khối lượng thuốc nổ cho 1 cấp vi sai. Bảng 4 trình bày hệ số tỉ lệ khoảng cách cho các mô hình dự báo khác nhau (QCVN 01:2019/BCT).

Từ kết quả giám sát được qua các đợt nổ mìn, hệ số tỉ lệ khoảng cách xác định cho hai mô hình đã trình bày ở trên và sử dụng phương pháp hồi quy, xác định được hệ số chấn động $K$ và chỉ số mũ $b$, giới thiệu trong Bảng 5 . Đồ thị Hình 5 biểu diễn mối quan hệ giữa tốc độ dao động lớn nhất PPV và hệ số khoảng cách giảm $(R / Q)$ và tăng $(Q / R)$.

Qua phân tích các mô hình ở trên, nhận thấy nhóm mô hình USBM và Ambraseys Hendron có hệ số $R^{2}$ cao và tương tự nhau, hệ số mũ cũng gần như nhau nhưng hệ số K lại khác nhau.
Bảng 2. Các thông số khoan nổ mìn thực hiện giám sát.

\begin{tabular}{|c|l|c|c|c|}
\hline TT & \multicolumn{1}{|c|}{ Tên chỉ tiêu } & $\begin{array}{c}\text { Ký } \\
\text { hiệu }\end{array}$ & Đơn vị & Giá trị \\
\hline 1 & Chiều cao tầng khai thác & $H_{t}$ & $\mathrm{~m}$ & $6 \div 7$ \\
\hline 2 & Tổng số lượng lỗ khoan & $N$ & lỗ & $20 \div 30$ \\
\hline 3 & Đường kính lỗ khoan & $d_{k}$ & $\mathrm{~mm}$ & 102 \\
\hline 4 & Chiều sâu lỗ khoan & $L_{l k}$ & $\mathrm{~m}$ & $6,7 \div 7,7$ \\
\hline 5 & Chiều sâu khoan thêm & $L_{k t}$ & $\mathrm{~m}$ & $0,5 \div 1$ \\
\hline 6 & Góc nghiêng lỗ khoan & $\beta$ & độ & 85 \\
\hline 7 & Đường kháng chân tầng & $W$ & $\mathrm{~m}$ & $2,9 \div 3,2$ \\
\hline 8 & $\begin{array}{l}\text { Khoảng cách giữa các lỗ } \\
\text { khoan }\end{array}$ & $a$ & $\mathrm{~m}$ & $2,9 \div 3,2$ \\
\hline 9 & $\begin{array}{l}\text { Khoảng cách giữa các } \\
\text { hàng lỗ khoan }\end{array}$ & $b$ & $\mathrm{~m}$ & $2,9 \div 3,2$ \\
\hline 10 & Chỉ tiêu thuốc nổ & $q$ & $\mathrm{~kg} / \mathrm{m}^{3}$ & $0,35 \div 0,37$ \\
\hline & $\begin{array}{l}\text { Tổng lương thuốc nổ } \\
\text { cho 1 lỗ khoan (cho } 1 \\
\text { cấp vi sai) }\end{array}$ & $Q$ & $\mathrm{~kg}$ & $21 \div 23$ \\
\hline
\end{tabular}

Bảng 3. Kết quả giám sát, khối lượng thuốc nổ một cấp vi sai và khoảng cách giám sát.

\begin{tabular}{|c|c|c|c|}
\hline TT & $\begin{array}{c}\text { Khoảng } \\
\text { cách đo } \\
R, \mathrm{~m}\end{array}$ & $\begin{array}{c}\text { Khối lượng thuốc } \\
\text { nổ lớn nhất cho } \\
\text { mối cấp vi sai } Q, \mathrm{~kg}\end{array}$ & $\begin{array}{c}\text { Tốc độ dao } \\
\text { động lớn nhất } \\
P P V, \mathrm{~mm} / \mathrm{s}\end{array}$ \\
\hline 1 & 155 & 23 & 8,92 \\
\hline 2 & 230 & 21 & 6,22 \\
\hline 3 & 155 & 21 & 10,9 \\
\hline 4 & 230 & 23 & 6,87 \\
\hline 5 & 300 & 23 & 4,9 \\
\hline 6 & 245 & 23 & 5,07 \\
\hline 7 & 200 & 23 & 4,99 \\
\hline 8 & 130 & 23 & 10,8 \\
\hline 9 & 180 & 23 & 7,53 \\
\hline 10 & 130 & 23 & 8,73 \\
\hline 11 & 460 & 23 & 1,4 \\
\hline 12 & 430 & 23 & 1,12 \\
\hline 13 & 420 & 23 & 1,18 \\
\hline 14 & 278 & 23 & 2,53 \\
\hline 15 & 130 & 23 & 9,21 \\
\hline
\end{tabular}

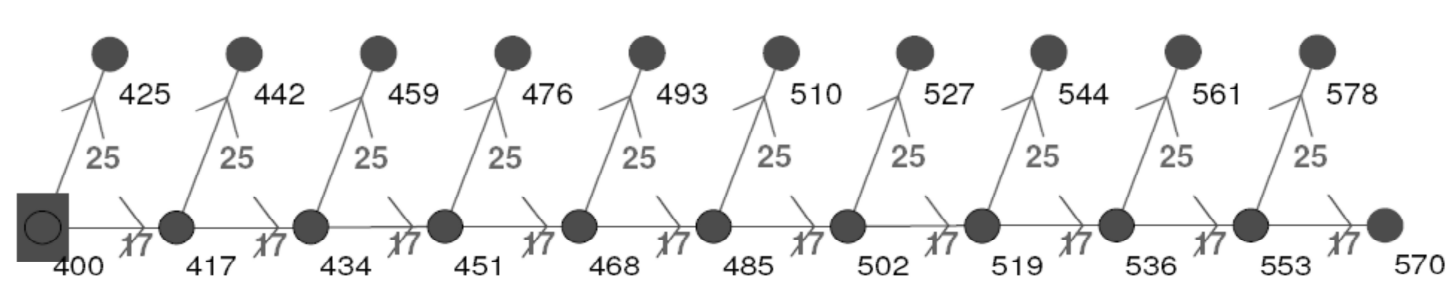

Hình 2. Sơ đồ đấu ghép mạng nổ sử dụng kíp nổ vi sai phi điện. 


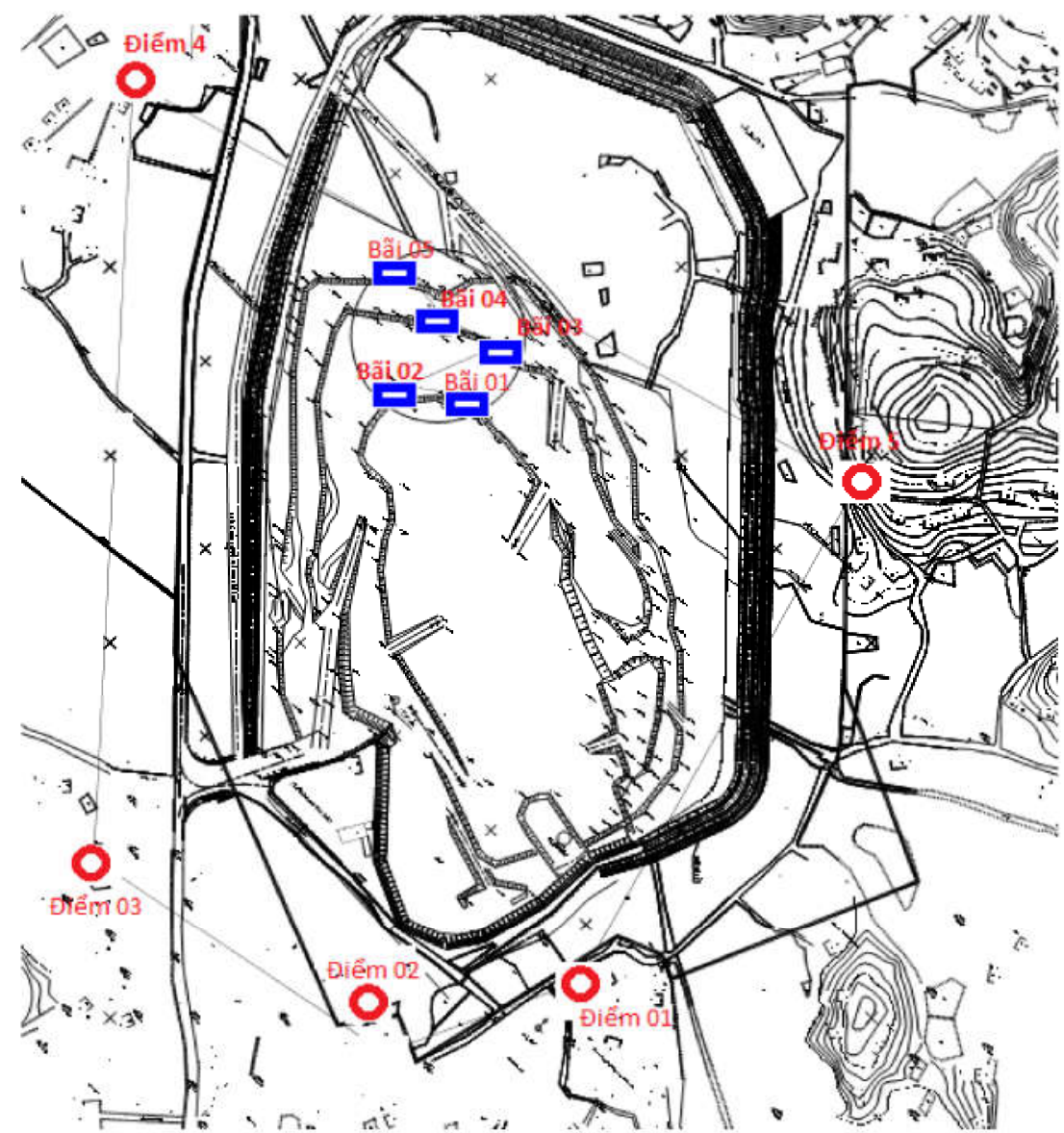

Hình 3. Vị trí thực hiện đo giám sát chấn động nổ mìn tại mỏ đá Ninh Dân.

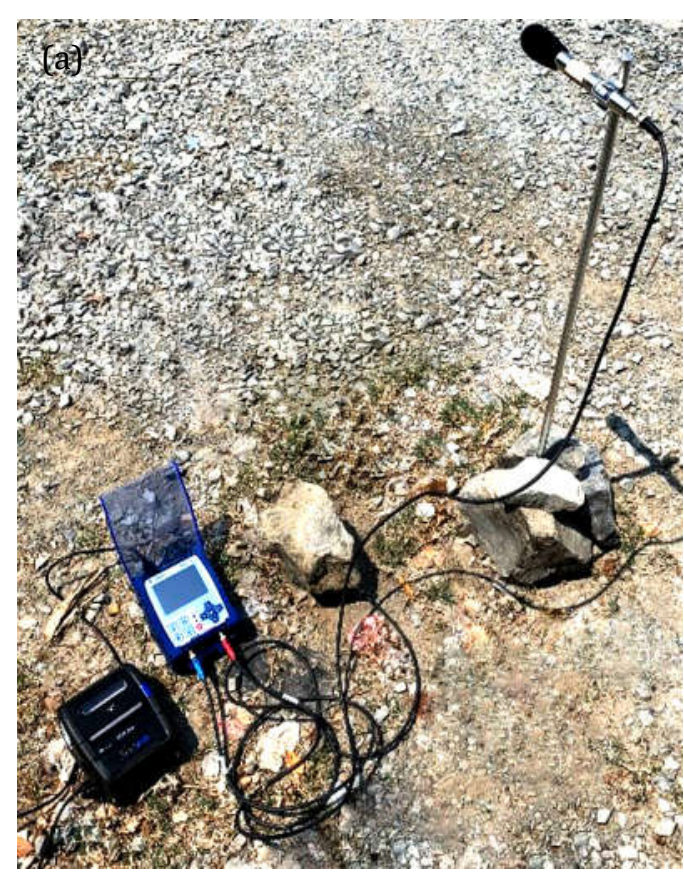

Hình 4. Hình ảnh và kết quả giám sát nổ mìn.

(a) Máy đo giám sát nổ min Micromate (Canada); (b) Kết quả đo giám sát nổ min tại mỏ đá Ninh Dân.

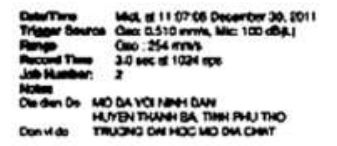

(b)
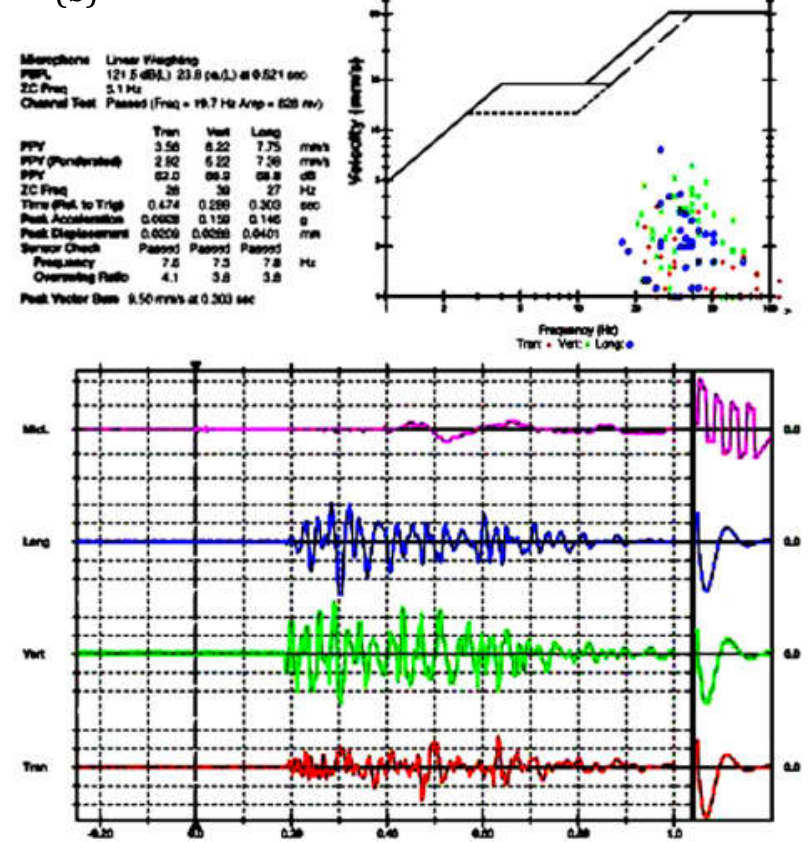
Bảng 4. Hệ số tỉ lệ khoảng cách với các mô hình dụ đoán khác nhau.

\begin{tabular}{|c|c|c|c|c|}
\hline \multirow{4}{*}{ TT } & \multicolumn{2}{|c|}{$\begin{array}{c}\text { Hệ số tỉ lệ khoảng } \\
\text { cách lũy tiến giảm } \\
\text { dần }(R / Q), D_{s}\end{array}$} & \multicolumn{2}{|c|}{$\begin{array}{c}\text { Hệ số tỉ lệ khoảng cách } \\
\text { tang lũy tiến }(Q / R), D_{s}\end{array}$} \\
\cline { 2 - 5 } & $\begin{array}{c}\text { USBM } \\
(1959)\end{array}$ & $\begin{array}{c}\text { Ambraseys } \\
\text { Hendron } \\
(1968)\end{array}$ & $\begin{array}{c}\text { Langefors- } \\
\text { Kihlstrom } \\
(1963)\end{array}$ & $\begin{array}{c}\text { Indian } \\
\text { Strandard } \\
(1973)\end{array}$ \\
\cline { 2 - 5 } & $\frac{R}{\sqrt{Q}}$ & $\frac{R}{\sqrt[3]{Q}}$ & & \\
\hline 1 & 32,32 & 54,50 & 0,89 & 0,80 \\
\hline 2 & 50,19 & 83,37 & 0,75 & 0,56 \\
\hline 3 & 33,82 & 56,18 & 0,85 & 0,73 \\
\hline 4 & 47,96 & 80,88 & 0,78 & 0,61 \\
\hline 5 & 62,55 & 105,49 & 0,72 & 0,51 \\
\hline 6 & 51,09 & 86,15 & 0,77 & 0,59 \\
\hline 7 & 41,70 & 70,33 & 0,82 & 0,67 \\
\hline 8 & 27,11 & 45,71 & 0,95 & 0,90 \\
\hline 9 & 37,53 & 63,29 & 0,85 & 0,72 \\
\hline 10 & 27,11 & 45,71 & 0,95 & 0,90 \\
\hline 11 & 95,92 & 161,75 & 0,62 & 0,39 \\
\hline 2 & 89,66 & 151,20 & 0,64 & 0,40 \\
\hline 13 & 87,58 & 147,69 & 0,64 & 0,41 \\
\hline 14 & 57,97 & 97,75 & 0,73 & 0,54 \\
\hline 15 & 27,11 & 45,71 & 0,95 & 0,90 \\
\hline & & & & \\
\hline
\end{tabular}

Bảng 5. Hệ số K và b của các mô hình dự doán khác nhau.

\begin{tabular}{|c|c|c|c|c|}
\hline TT & $\begin{array}{c}\text { Mô hình dự } \\
\text { đoán }\end{array}$ & Hệ số $K$ & $\begin{array}{c}\text { Hệ số } \\
\text { mũ } b\end{array}$ & $\begin{array}{c}\text { Hệ số tương } \\
\text { quan } R^{2}\end{array}$ \\
\hline 1 & USBM & 667,75 & $-1,32$ & 0,71 \\
\hline 2 & $\begin{array}{c}\text { Ambraseys } \\
\text { and Hendron }\end{array}$ & 1353,3 & $-1,33$ & 0,71 \\
\hline 3 & $\begin{array}{c}\text { Langefors- } \\
\text { Kihlstrom }\end{array}$ & 10,0478 & 3,87 & 0,68 \\
\hline 4 & $\begin{array}{c}\text { Tiêu chuẩn Ấn } \\
\text { Độ }\end{array}$ & 10,478 & 1,93 & 0,68 \\
\hline
\end{tabular}

Nhóm mô hình Langefors-Kihlstrom và Indian Strandard có giá trị $R^{2}$ và hệ số chấn động $K$ giống nhau nhưng hệ số mũ $b$ lại khác nhau.

Mục đích chính trong nghiên cứu này sử dụng các mô hình dự báo khác nhau để xác định quy mô một đợt nổ mìn hợp lý với tốc độ dao động nền đất lớn nhất nằm trong giới hạn cho phép. Trên cơ sở các kết quả giám sát từ các đợt nổ, sử dụng phương pháp kiểm chứng chéo để ước tính tốc độ dao động lớn nhất cho 4 mô hình trên (Hình 6). Qua kết quả nghiên cứu nhận thấy các mô hình USBM và Ambraseys Hendron có hệ số $R^{2}=0,79$ và các mô hình Indian Strandard và Langefors có hệ số $R^{2}=0,74$.

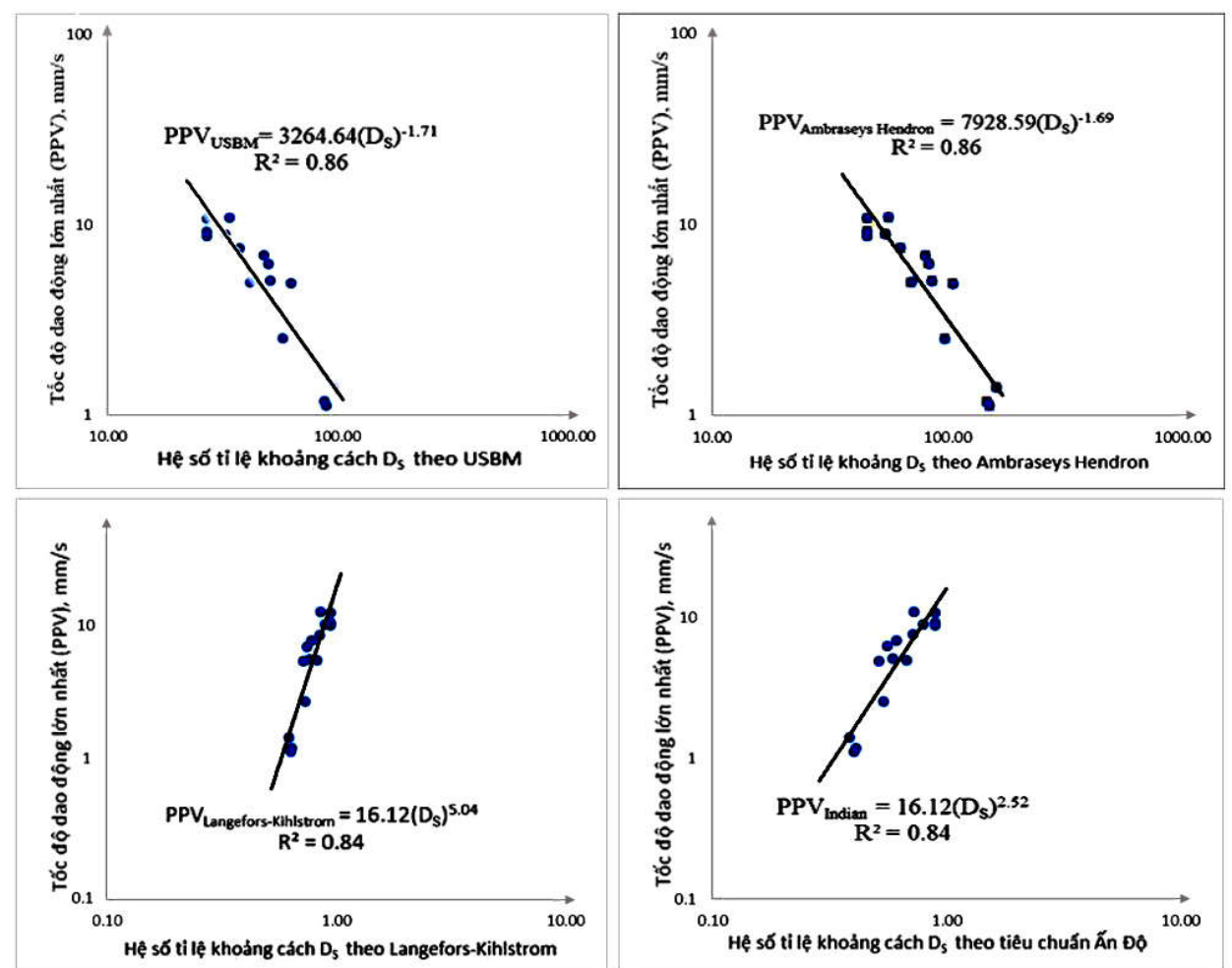

Hình 5. Đồ thị biểu diễn mối quan hệ giữa tốc độ dao động lón nhất PPV và hệ số tỉ lệ khoảng cách $D_{s}$ với các mồ hình khác nhau. 

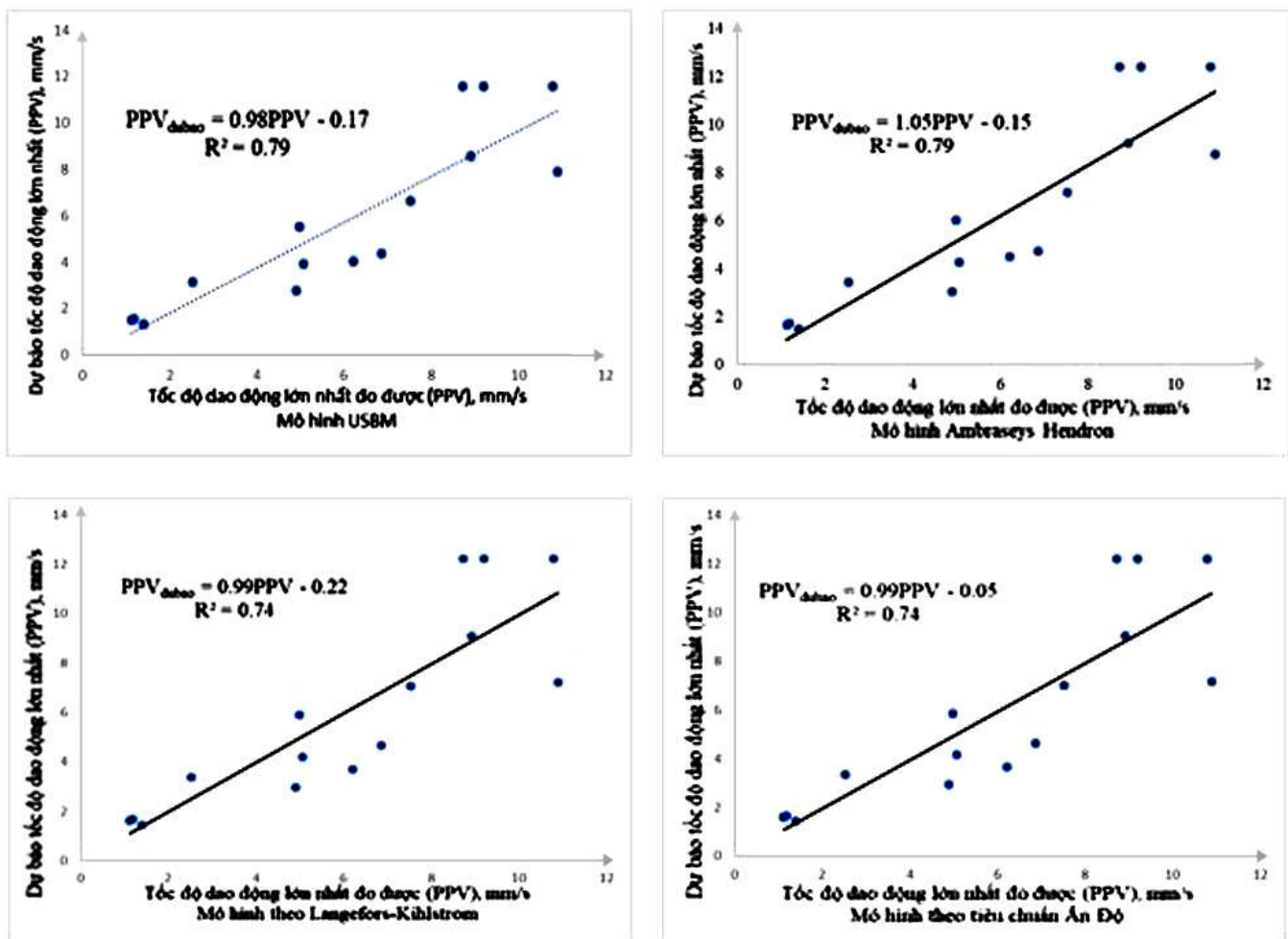

Hình 6. Đồ thị kiểm chứng chéo giữa hệ số tỉ lệ khoảng cách tăng và giảm với tốc độ dao động với các mô hình khác nhau.

Với các kết quả phân tích trên ta nhận thấy, để dự báo tốc độ dao động lớn nhất của các vụ nổ tiếp theo nên sử dụng các mô hình USBM và Ambraseys Hendron vì có độ tin cậy cao hơn.

\section{Kết luận}

1. Tiêu chuẩn tổng quát nhất đánh giá tác dụng chấn động khi nổ mìn là tốc độ dao động lớn nhất (PPV, mm/s) của nền công trình cần bảo vệ. Hai thông số quyết định đến tốc độ dao động của nền đất là khối lượng thuốc nổ $Q(\mathrm{~kg})$ và khoảng cách đo từ vị trí nổ mìn đến điểm đo $R(\mathrm{~m})$.

2. Trên cơ sở những số liệu đo được từ các vụ nổ của mỏ đá vôi Ninh Dân, qua việc sử dụng các mô hình khác nhau để đánh giá dự báo tốc độ dao động nền đất, tác giả đề nghị sử dụng các mô hình dự báo USBM và Ambraseys Hendron, dựa trên hệ số tỉ lệ khoảng cách giảm lũy tiến là tỉ số giữa khoảng cách và khối lượng thuốc nổ cho một đợt nổ vi sai $(R / Q)$, để dự báo tốc độ dao động của nền đất có độ chính xác cao hơn các mô hình khác khi tiến hành nổ mìn tại mỏ đá vôi Ninh Dân.

3. Kết quả nghiền cứu của nhóm tác giả cũng là cơ sở khoa học để lựa chọn, tính toán áp dụng cho các mỏ đá vôi khác ở Việt Nam có điều kiện nổ mìn khai thác tương tự mỏ đá vôi Ninh Dân, huyện Thanh Ba, tỉnh Phú Thọ.

\section{Lời cảm ơn}

Nhóm tác giả xin cảm ơn các cán bộ phòng kỹ thuật khai thác tại mỏ đá vôi Ninh Dân huyện Thanh $\mathrm{Ba}$, tỉnh Phú Thọ đã cung cấp các tài liệu và phối hợp giúp đỡ chúng tôi trong quá trình đo đạc, giám sát nổ mìn thực nghiệm tại mỏ để hoàn thành bài báo này.

\section{Tài liệu tham khảo}

An toàn trong sản xuất, thử nghiệm, nghiệm thu, bảo quản, vận chuyển, sử dụng, tiêu hủy vật liệu nổ công nghiệp và bảo quản tiền chất thuốc nổ- QCVN 01:2019/BCT.

Dehghani, H., (2011). Development of a model to predict peak particle velocity in a blasting operation. International Journal of Rock Mechanics \& Mining Sciences 48, 51-58.

Drukovanui, M. F., (1973). Methods for controlling the explosion in quarries. Publisher. Moscow, Russian. 
Ganaponxki, M. I., Paron, B. L., Belin, V. A., Pukop V. V., Xivenkop M. A., (2007). Methods of blasting. Special blasting operations, MGGU. Moscow, Russian.

Khandelwal, M. \& Singh, T. N., (2007). Evaluation of blast-induced ground vibration predictors. Soil Dynamics and Earthquake Engineering 27(2), 116-125.

Khandelwal, M. \& Singh, T. N., (2009). Prediction of blast-induced ground vibration using artificial neural network. International Journal of Rock Mechanics \& Mining Sciences 46(7), 1214-1222.

Kutuzov, B. N, (1992). Blasting of rock. Moscow university of mining. Publisher. Moscow, Russian.

Nguyễn Đình An, Trần Quang Hiếu, Trần Khắc Hùng (2011). Một số phương pháp xác định vận tốc dao động cực đại gây ra bởi chấn động nổ mìn trong khai thác mỏ lộ thiên. Tuyển tập báo cáo Hội nghi khoa học kỹ thuật mỏ toàn Quốc lần thúu 22.

Nhữ Văn Bách (cb) (2015). Công nghệ khoan - nổ mìn hiện đại với lỗ khoan đường kính lớn áp dụng cho các mỏ khai thác đá vật liệu xây dựng
Việt Nam. Nhà xuất bản khoa học tự nhiên và công nghệ. 2015.

Nhữ Văn Bách (2013). Nghiên cứu hoàn thiện công nghệ khoan - nổ mìn lỗ khoan đường kính lớn áp dụng cho mỏ đá lộ thiên gần khu vực dân cư ở Việt Nam. Đề tài cấp nhà nước, mã số ĐT.01-11/ĐMCNK. Hà Nội. 2013.

Nhữ Văn Bách, Bùi Xuân Nam, Nguyễn Đình An, Trần Khắc Hùng (2012). Phương pháp xác định tốc độ dao động của nền đất khi nổ mìn vi sai phi điện. Tạp chí Khoa học Kỹ thuật Mỏ - Địa chất 38.

Nhu Van Bach, Le Van Quyen, Nguyen Dinh An, (2006). Methods for increasing effect and minimizing impacts of ground vibrations when blasting at the Nui Beo surface coal mine. Project between Hanoi University of Mining and Geology and Nui Beo surface coal mine.

Stig O Olofsson, (1997). Applied explesive technology for construction and mining, Publisher Applex P.O. Box 71 S-640, Sweeden.

Xadopski, M. A., (2004). The mechanical action of air shock waves of explosion according to experimental studies. Publisher. Moscow, Russian. 